Chronic Obstructive Pulmonary Diseases: Journal of the COPD Foundation COOPDD

\author{
Original Research
}

\title{
The Association of Multiparity with Lung Function and Chronic Obstructive Pulmonary Disease-Related Phenotypes
}

\author{
Matthew Moll, MD ${ }^{1,2}$ Elizabeth A. Regan, MD, $\mathrm{PhD}^{3}$ John E. Hokanson, $\mathrm{PhD}^{4}$ Sharon M. Lutz, $\mathrm{PhD}^{5}$ \\ Edwin K. Silverman, MD, PhD ${ }^{1,2,6}$ James D. Crapo, MD ${ }^{7}$ Barry J. Make, MD ${ }^{7}$ Dawn L. DeMeo, MD, MPH ${ }^{1,2}$
}

\begin{abstract}
Background: Apparent increased female susceptibility to chronic obstructive pulmonary disease (COPD) suggests sex hormones modulate disease pathogenesis. Little is known about associations between multiparity and lung function in smokers.
\end{abstract}

Research Question: We hypothesized that multiparity is associated with lung function and measures of emphysema and airway disease.

Study Design and Methods: Utilizing female participants from the 5-year follow up of the COPD Genetic Epidemiology (COPDGene ${ }^{\circledast}$ ) study we performed multivariable linear regressions to assess the effect of multiparity and number of pregnancies on forced expiratory volume in 1 second $\left(F E V_{1}\right)$ percentage of predicted (\% predicted), $\mathrm{FEV}_{1}$ /forced vital capacity (FVC), percent emphysema on computed tomography (CT) scans, and Pi10, a measure of airway thickening. We sampled never smokers and those with lower smoking exposure from the National Health and Nutrition Examination Survey (NHANES) 2011-2012 dataset.

Results: We included 1820 participants from COPDGene ${ }^{\circledR}$ and 418 participants from NHANES (321 never smokers, 97 ever smokers). In COPDGene ${ }^{\oplus}$, multiparity (beta coefficient $[\beta]=-3.8,95 \%$ confidence interval

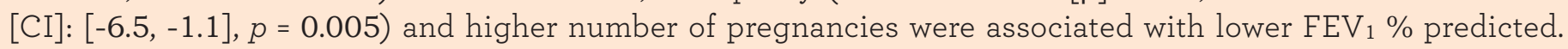
Multiparity was not associated with percent emphysema or Pi10. In individuals with no or mild obstruction, multiparity was associated with lower $\mathrm{FEV}_{1} \%$ predicted. There was an interaction with multiparity and age on $\mathrm{FEV}_{1} \%$ predicted $(p=0.025)$. In NHANES, there was no association between multiparity and $\mathrm{FEV}_{1} \%$ predicted in never smokers or the lower smoking exposure group.

Interpretation: Multiparity was associated with lower $\mathrm{FEV}_{1} \%$ predicted in current and former smokers in COPDGene ${ }^{\circledast}$ study participants. These preliminary results emphasize the importance of smoking abstinence in women of child-bearing age.

\footnotetext{
Abbreviations: chronic obstructive pulmonary disease, COPD; COPD Genetic Epidemiology, COPDGene ${ }^{\circledR}$ forced expiratory volume in 1 second, FEV1; percentage of predicted, \% predicted; forced vital capacity, FVC; computed tomography, CT; square root of the wall area of a hypothetical airway with an internal perimeter of $10 \mathrm{~mm}$, Pi10; National Health and Nutrition Examination Survey, NHANES; beta coefficient, $ß$; confidence interval, CI; forced expiratory flow at $25 \%-75 \%$ of the maneuver, $\mathbf{F E V}_{\mathbf{2 5}} \mathbf{- 7 5}$; preserved ratio-impaired spirometry, PRISm; low attenuation area, LAA; Hounsfield units, HU; body mass index, BMI; 6-minute walk test distance, 6MWD; pregnancy-associated plasma protein-A, PAPP-A; antigen presenting cells, APCs

Funding Support: The COPDGene ${ }^{\circledR}$ study is supported by Award Number U01 HL089897 and Award Number U01 HL089856 from the National Heart, Lung, and Blood Institute. The content is solely the responsibility of the authors and does not necessarily represent the official views of the National Heart, Lung, and Blood Institute or the National Institutes of Health. The COPDGene ${ }^{\circledR}$ study is also supported by the COPD Foundation through contributions made to an Industry Advisory Board comprised of AstraZeneca, Boehringer-Ingelheim, Genentech, GlaxoSmithKline, Novartis, Pfizer, Siemens, and Sunovion.

Date of Acceptance: January 22, 2020

Citation: Moll M, Regan EA, Hokanson JE, et al. The association of multiparity with lung function and chronic obstructive pulmonary disease-related phenotypes. Chronic Obstr Pulm Dis. 2020;7(2):86-98. doi: https://doi.org/10.15326/jcopdf.7.2.2019.0166
} 
1 Channing Division of Network Medicine, Brigham and Women's Hospital, Boston, Massachusetts

2 Division of Pulmonary and Critical Care Medicine, Brigham and Women's Hospital, Boston, Massachusetts

3 Division of Rheumatology, National Jewish Health, Denver, Colorado

4 Department of Epidemiology, Colorado School of Public Health, University of Colorado Anschutz Medical Campus, Aurora

5 PRecisiOn Medicine Translational Research (PROMoTeR) Center, Department of Population Medicine, Harvard Medical School and Harvard Pilgrim Health Care, Boston, Massachusetts

6 Harvard Medical School, Boston, Massachusetts

7 Division of Pulmonary, Critical Care and Sleep Medicine, National Jewish Health, Denver, Colorado

\section{Address correspondence to:}

Dawn L. DeMeo, MD, MPH

Harvard Medical School

Brigham and Women's Hospital

Phone: (617) 525-0866

Email: dawn.demeo@channing.harvard.edu

\section{Keywords:}

chronic obstructive pulmonary disease; COPD; multiparity; pregnancy; female; hormones; phenotypes

\section{Note: This article has an online supplement.}

\section{Introduction}

Chronic obstructive pulmonary disease (COPD) is characterized by persistent airflow limitation, and often related to smoking exposure. ${ }^{1}$ The pathogenetic mechanisms of COPD remains an active area of investigation, though inflammation, oxidative stress, protease/anti-protease imbalance, autoimmunity, and accelerated aging are implicated. ${ }^{2}$ COPD was previously thought to be a disease of older males. However, the rise of smoking in females has narrowed the prevalence gap between sexes, ${ }^{3}$ and the importance of sex-specific differences in COPD susceptibility and pathophysiology has become apparent. ${ }^{4-6}$ In adolescents, smoking is associated with reduced lung growth in females compared to males. ${ }^{7}$ A differential decline in lung function is also seen in adult females and males, particularly amongst heavy smokers. ${ }^{8}$ In a family-based cohort of 84 probands with severe, early-onset COPD (age < 52 years, forced expiratory volume in 1 second $\left[\mathrm{FEV}_{1}\right]<40$ percent predicted[\% predicted]), $60(71 \%)$ probands were female 9,10 despite lower overall smoking history.

A subsequent analysis in 2500 participants from the COPD Genetic Epidemiology (COPDGene ${ }^{\circledR}$ ) study reported that $66 \%$ of early-onset COPD participants (age $<55$ years, $\mathrm{FEV}_{1}<50 \%$ ) were female. Additionally, maternal smoking, and maternal COPD were associated with early-onset COPD. ${ }^{11}$ Phenotypically, female smokers are more likely to be hospitalized for COPD exacerbations, ${ }^{12}$ have more dyspnea, higher mortality risk, and worse functional status. ${ }^{13}$ These data suggest that female sex, hormonal factors, and age may affect susceptibility to and manifestations of smoking-related lung disease.

Sex-specific hormonal factors may alter COPD susceptibility through several mechanisms. ${ }^{14}$ Cigarette smoke contains thousands of compounds, many of which are activated to their toxic form by phase I cytochrome P450 enzymes (bioactivation). Detoxification of these metabolites is mediated by Phase II enzymes. ${ }^{15,16}$ However, in human lungs, estradiol upregulates P450 enzymes without significantly changing expression of Phase II enzymes. ${ }^{17,18}$ This may lead to increased oxidative stress in the lungs, placing females at higher risk for COPD despite lower overall pack years of smoking.

While there is evidence of sex differences in COPD, and hormonal factors are mechanistically implicated, little is known regarding female hormonal effects in population studies. Recently, menopause has been associated with accelerated $\mathrm{FEV}_{1}$ decline. ${ }^{19}$ Pregnancy represents a time of high hormonal exposure, and multiparity has been associated with lower lung function during pregnancy. A longitudinal prospective study of 120 pregnant women reported that, in multiparous compared to nulliparous women, the forced expiratory flow in $25 \%$ to $75 \%$ of the maneuver $\left(\mathrm{FEF}_{25-75}\right)$ was lower in both the first (3.2 L versus $3.7 \mathrm{~L}, p=0.0005)$ and third (3.3 L versus $3.6 \mathrm{~L}$, $p=0.031$ ) trimesters; however, there was no postpartum follow-up of lung function. ${ }^{20}$ These data provide evidence that endogenous hormones and pregnancy may affect lung function.

We hypothesized that, in smokers, multiparity is associated with reduced lung function and quantitative computed tomography (CT) imaging measures of emphysema and airway disease. We performed an analysis in smokers with and without COPD from the COPDGene ${ }^{\circledR}$ study to understand the effects of number of pregnancies and multiparity on measures of COPD disease severity and progression. As we did not expect to observe these effects in never smokers, we also evaluated associations between multiparity 
and lung function in never smokers and those with lower smoking exposure from a subset of National Health and Nutrition Examination Survey (NHANES) participants.

\section{Methods}

\section{Study Participants}

\section{COPD Genetic Epidemiology Study}

We included female participants from the 5-year follow-up of the COPDGene ${ }^{\circledast}$ study. Details regarding the COPDGene ${ }^{\circledR}$ study design have been previously published. ${ }^{21}$ Briefly, participants were non-Hispanic whites or African Americans, 45 to 80 years of age at Phase 1 enrollment, with 10 or more pack years of smoking history, recruited from 21 U.S. clinical sites. COPDGene $^{\circledast}$ includes smokers with and without obstruction, including those with normal spirometry $\left(\mathrm{FEV}_{1} \geq 80 \%\right.$ predicted and $\left.\mathrm{FEV}_{1} / \mathrm{FVC}>0.7\right)$, those with preserved ratio-impaired spirometry $\left(\mathrm{FEV}_{1}<\right.$ 80\% predicted and $\mathrm{FEV}_{1} / \mathrm{FVC}>0.7$; aka "PRISm"), and those with Global initiative for chronic Obstructive Lung Disease (GOLD)-defined COPD ( $F_{1}$ /FVC < 0.7). ${ }^{1}$ Baseline demographic, clinical, spirometric, and imaging variables were initially collected (Phase 1, $\mathrm{n}=10,192$ ), and then re-measured after 5 years (Phase $2, \mathrm{n}=5000$ ). At the 5-year follow up of COPDGene ${ }^{\circledR}$, questions about pregnancy and menstrual cycles were adapted from standardized and validated questionnaires. $^{22}$ Inclusion criteria for this current analysis included being a Phase 2 participant ( $\mathrm{n}=$ 5000), female sex ( $n=2487$ ), and having answered the questions regarding parity $(\mathrm{n}=1833)$. We excluded individuals reporting more than 10 pregnancies ( $\mathrm{n}=$ 13) as grand multiparity is associated with numerous poor outcomes, ${ }^{23}$ and there is a paucity of studies that included women with this range of numbers of pregnancies. The final number of female participants included is 1820 (Figure 1).

\section{National Health and Nutrition Examination Survey}

To assess generalizability in individuals with lower or no smoking exposure, we included non-Hispanic white participants $\geq 45$ years of age with spirometry data and similar questions about pregnancy available in the NHANES 2011-2012 dataset. We included weights for individuals in the regression models to account for ascertainment bias due to study design. ${ }^{24}$ Spirometry values were converted to percent predicted

\section{Figure 1. Schematic of Inclusion and Exclusion Criteria for Participants from COPDGene ${ }^{\circledR}$ and National Health and Nutrition Examination Survey}

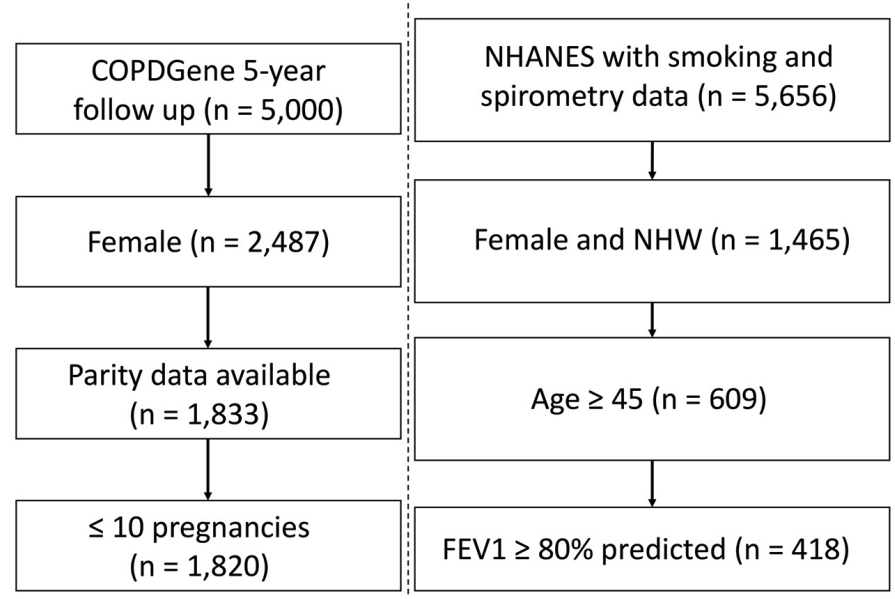

$\mathrm{FEV}_{1}=$ forced expiratory volume in 1 second; NHANES=National Health and Nutrition Examination Survey; NHW=non-Hispanic whites

values using Hankinson reference equations. ${ }^{25}$ We classified participants into GOLD spirometry grades ${ }^{1}$ based on pre-bronchodilator $\mathrm{FEV}_{1} \%$ predicted and $\mathrm{FEV}_{1} / \mathrm{FVC}$. We defined a "lower smoking exposure" group as those with $\geq 100$ cigarettes in a lifetime, and only included those with no or mild obstruction (FEV 1 $\geq 80 \%$ predicted); these participants had less than a mean of 10 pack years of smoking history.

\section{Study Design and Analyses}

Our conceptual model is shown in Figure 2. Based on this framework, we performed the below epidemiological analyses.

Exposure Variables: We conducted an analysis of the effects of number of pregnancies and multiparity on lung function and quantitative CT imaging variables. Specific questions asked are shown in eTable S1 in the online data supplement. We considered 2 representations for the exposure, parity. (1) The number of times pregnant was transformed into a categorical variable ( 1 or fewer pregnancies, 2 pregnancies, 3 or more pregnancies), and 1 or fewer pregnancies was used as the reference group since only 13 participants reported zero pregnancies. (2) Multiparity was defined as $>1$ pregnancy, with 1 or fewer as the reference group. 


\section{Figure 2. Conceptual Model of the Relationship Between Parity and Low Lung Function, COPD and Emphysema}

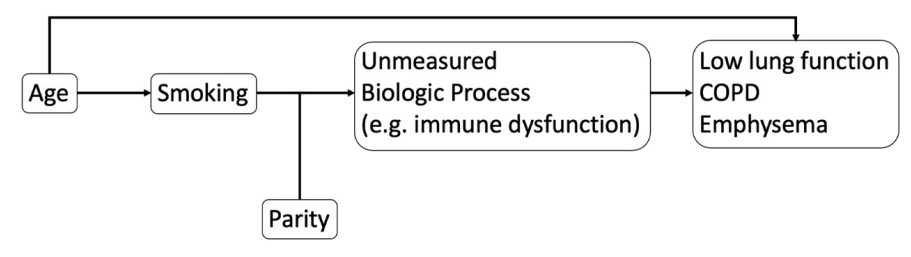

$\mathrm{COPD}=$ chronic obstructive lung disease

Outcome Variables: The primary outcome in COPDGene $^{\circledast}$ was the post-bronchodilator $\mathrm{FEV}_{1} \%$ predicted. Secondary outcomes included FEV $1 / F V C$ ratio, percentage of emphysema on $\mathrm{CT}$ imaging (\% low attentuation area $[\mathrm{LAA}]<-950$ Hounsfield units $[\mathrm{HU}]),{ }^{26}$ and the square root of the wall area of a hypothetical airway with an internal perimeter of 10 $\mathrm{mm}$ (Pi10). ${ }^{27}$ Spirometry measures were obtained from the 5-year follow up visit of the COPDGene ${ }^{\circledast}$ study. In NHANES, the outcomes explored included $\mathrm{FEV}_{1} \%$ predicted and $\mathrm{FEV}_{1} / \mathrm{FVC}$ ratio.

Primary Analyses: To determine the effects of number of pregnancies and multiparity on lung function and quantitative CT imaging variables in the COPDGene ${ }^{\circledast}$ study, we fit linear regression models for each outcome and exposure variables defined above adjusting for age, pack years of smoking, body mass index (BMI), current smoking status, age at which smoking was started, and level of education completed. In addition, we stratified our data into "controls" (no obstruction or GOLD spirometry grade 1 ), PRISm, ${ }^{28}$ and GOLD 2-4 (“Cases"), and then repeated our analyses within these groups. In NHANES, we also included never smokers and lower smoking exposure groups to investigate the effect of parity in these populations. For linear regression models in NHANES, we adjusted for age, pack years of smoking, current smoking, BMI, and level of education. Beta coefficients ( $\beta$ ) and 95\% confidence intervals (CIs) were reported. Variables with a pre-specified threshold $p$-value of less than 0.05 were considered significant.

Interaction Analyses: We also considered the interaction of multiparity and age, pack years of smoking, or smoking start age on lung function. Each potential interaction was evaluated in a separate linear regression model that included multiparity, the potential interaction variable (i.e. age, pack years of smoking, or smoking start age), and an interaction term. For example, to assess for an interaction between pack years of smoking and multiparity in relation to a given outcome, the regression model would include multiparity, pack years, multiparity x pack years (the interaction term), and relevant covariates. Interaction terms were considered significant if the $p$ value was less than 0.05 .

\section{Results}

\section{Characteristics of Participants}

Characteristics of COPDGene ${ }^{\circledR}$ participants are shown in Table 1. There were 928 smoker controls (no or mild obstruction), 220 PRISm, and 616 GOLD 2-4 COPD cases enrolled at the 5-year follow-up for COPDGene ${ }^{\circledR}$ that met our selection criteria (Figure 1, total $n=1820$ ). Compared to controls (no or mild obstruction), COPD participants (GOLD 2-4) were slightly older, had more pregnancies, similar number of postmenopausal women, more pack years of smoking history, and lower 6-minute walk test distance (6MWD).

Characteristics of NHANES participants $(n=418)$ are shown in supplemental eTable S2 in the online supplement. There were 321 never smokers and 97 participants in the lower smoking exposure group. Compared to the group with no or mild obstruction in COPDGene ${ }^{\circledR}$, the NHANES population was slightly younger, and had fewer pack years of smoking (mean 8 versus 37 pack years) and had a fewer number of individuals with 1 or fewer pregnancies.

\section{Association of Parity with Lung Function}

In the overall analysis, including all 1820 COPDGene ${ }^{\circledR}$ participants, having 2 pregnancies $(\beta=-3.1,95 \% \mathrm{CI}$ : $[-6.1,-0.03], p=0.048)$ or 3 or more pregnancies $(\beta=$ $-4.5,95 \%$ CI: $[-7.4,-1.5], p=0.003)$ are associated with a lower FEV 1 \% predicted (Table 2). Multiparity ( $\beta=$ $-3.8,95 \%$ CI: $[-6.5,-1.1], p=0.005)$ is associated with a lower $\mathrm{FEV}_{1} \%$ predicted (Table 3 ). In the stratified analyses, having 2 or 3 or more pregnancies and multiparity are significantly associated with lower $\mathrm{FEV}_{1} \%$ predicted in participants with no or mild obstruction (Tables 2 and 3 ) but not across the more severe GOLD grades. For the interaction analyses, the interaction of multiparity with age on $\mathrm{FEV}_{1} \%$ predicted was significant $(\beta=-0.23,95 \%$ CI: $[-0.86,0.4]$, 


\section{Table 1. Characteristics of COPDGene ${ }^{\circledR}$ Participants Included in This Study ${ }^{\mathrm{a}}$}

\begin{tabular}{|c|c|c|c|}
\hline & Control & PRISm & COPD \\
\hline n & 928 & 220 & 616 \\
\hline Age in Years (mean [SD]) & $64.98(8.86)$ & $62.16(8.20)$ & $67.51(8.40)$ \\
\hline \multicolumn{4}{|l|}{ Number of Times Pregnant (\%) } \\
\hline 1 or less & 218 (23.5) & 47 (21.4) & 107 (17.4) \\
\hline 2 & $319(34.4)$ & $60(27.3)$ & $206(33.4)$ \\
\hline 3 or more & $391(42.1)$ & $113(51.4)$ & $303(49.2)$ \\
\hline Multiparity (>1 pregnancy) & $710(76.5)$ & $173(78.6)$ & $509(82.6)$ \\
\hline Postmenopausal (Number [\%]) & $829(89.3)$ & $190(86.4)$ & $569(92.4)$ \\
\hline Body Mass Index $\left(\mathrm{kg} / \mathrm{m}^{2}\right)$ (mean [SD]) & $29.30(6.45)$ & $32.32(7.67)$ & $28.58(7.21)$ \\
\hline Current Smoking Status (Number [\%]) & $363(39.1)$ & $118(53.6)$ & $200(32.5)$ \\
\hline Age Started Smoking (mean [SD]) & $17.21(4.16)$ & $17.11(4.89)$ & $16.82(4.00)$ \\
\hline Pack Years of Smoking (mean [SD]) & $37.20(20.15)$ & $40.18(23.43)$ & $48.13(22.52)$ \\
\hline \multicolumn{4}{|l|}{ GOLD Spirometry Severity $(\%)$} \\
\hline PRISm & $0(0.0)$ & $220(100.0)$ & $0(0.0)$ \\
\hline $\mathbf{0}$ & $792(85.3)$ & $0(0.0)$ & $0(0.0)$ \\
\hline 1 & $136(14.7)$ & $0(0.0)$ & $0(0.0)$ \\
\hline 2 & $0(0.0)$ & $0(0.0)$ & $374(60.7)$ \\
\hline 3 & $0(0.0)$ & $0(0.0)$ & $174(28.2)$ \\
\hline 4 & $0(0.0)$ & $0(0.0)$ & $68(11.0)$ \\
\hline FEV $_{1}, \%$ Predicted (mean [SD]) & $96.44(11.52)$ & $69.77(8.40)$ & $52.94(16.47)$ \\
\hline 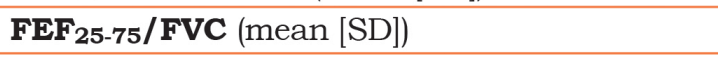 & $1.97(0.84)$ & $1.41(0.50)$ & $0.48(0.26)$ \\
\hline FEV $_{1}$ / FVC ratio (mean [SD]) & $0.77(0.07)$ & $0.76(0.05)$ & $0.53(0.12)$ \\
\hline DLCO (mean [SD]) & $82.09(19.21)$ & $74.46(19.05)$ & $58.47(21.01)$ \\
\hline 6-Minute Walk Distance (meters) (mean [SD]) & $1364.91(397.11)$ & $1168.51(392.40)$ & $1047.04(450.27)$ \\
\hline Attended College or Above (No. [\%]) & $635(68.4)$ & $122(55.5)$ & $353(57.3)$ \\
\hline
\end{tabular}

$\mathrm{a}_{\mathrm{n}=1820 \text { total }}$

Participants are stratified by control (no or mild obstruction), PRISm, and COPD case (GOLD 2-4) status.

PRISm=preserved ratio-impaired spirometry; $\mathrm{COPD}=$ chronic obstructive pulmonary disease; $\mathrm{SD}=$ standard deviation; GOLD=Global initiative for chronic Obstructive Lung Disease; $\mathrm{FEV}_{1}=$ forced expiratory volume in 1 second;

$\mathrm{FEF}=$ forced expiratory flow at $25 \%-75 \%$ of $\mathrm{FVC}$; FVC=forced vital capacity; DLCO=diffusing capacity for carbon monoxide

$p=0.025)$. Figures 3A, 3B, 3C and 3D show boxplots of $\mathrm{FEV}_{1} \%$ predicted in each age quintile, separated by multiparity status. Multiparity was associated with lower $\mathrm{FEV}_{1} \%$ predicted, particularly in lower (5763 years) and higher (74-90 years) age categories. Interactions of multiparity with smoking or smoking start age on $\mathrm{FEV}_{1} \%$ predicted were not significant.

None of the exposure variables were associated with $\mathrm{FEV}_{1} / \mathrm{FVC}$ ratio (eTable S3 in the online supplement). Multiparity or number of pregnancies were not associated with percent emphysema (\% LAA < -950 $\mathrm{HU})$ (eTable S4 in the online supplement) or airway wall measurement (Pi10) (eTable S5 in the online supplement) in overall analyses. In GOLD 2-4 participants, multiparity was associated with higher $\operatorname{Pi} 10(\beta=0.24,95 \%$ CI: $[0.05,0.42], p=0.01)$. In the never and lower smoking exposure groups from NHANES, neither multiparity or number of pregnancies were associated with $\mathrm{FEV}_{1} \%$ predicted or $\mathrm{FEV}_{1} / \mathrm{FVC}$ ratio (Table 4 and eTable $S 6$ in the online supplement).

\section{Discussion}

In this study, we examined the association between parity and lung function within 1820 smokers in the COPDGene ${ }^{\circledast}$ study. We found that, in current and former smoking women from the COPDGene ${ }^{\circledast}$ study with no or mild airflow obstruction, multiparity was 


\section{Table 2. The Association of Number of Pregnancies and Main Effects of Smoking with Forced Expiratory Volume in One Second Percent Predicted in COPDGene ${ }^{\circledR}$ Participants}

\begin{tabular}{|c|c|c|c|c|c|c|c|c|}
\hline \multirow[t]{2}{*}{ Predictor } & \multicolumn{2}{|l|}{ All } & \multicolumn{2}{|c|}{ No or Mild Obstruction } & \multicolumn{2}{|l|}{ PRISm } & \multicolumn{2}{|c|}{ GOLD Stages 2-4 } \\
\hline & Adj $\beta(95 \% \mathrm{Cl})$ & $p$ value & $\operatorname{Adj} \beta(95 \% \mathrm{Cl})$ & $p$ value & $\operatorname{Adj} \beta(95 \% \mathrm{Cl})$ & $p$ value & $\operatorname{Adj} \beta(95 \% \mathrm{Cl})$ & $p$ value \\
\hline 2 Pregnancies & $\begin{array}{r}-3.1 \\
(-6.1,-0.033)\end{array}$ & 0.048 & $\begin{array}{r}-2.5 \\
(-4.6,-0.37)\end{array}$ & 0.021 & $\begin{array}{r}-0.36 \\
(-3.5,2.8)\end{array}$ & 0.82 & $\begin{array}{r}-1.9 \\
(-5.5,1.7)\end{array}$ & 0.3 \\
\hline $\begin{array}{l}3 \text { or More } \\
\text { Pregnancies }\end{array}$ & $\begin{array}{r}-4.5 \\
(-7.4,-1.5)\end{array}$ & 0.0028 & $\begin{array}{r}-2.7 \\
(-4.8,-0.67)\end{array}$ & 0.0094 & $\begin{array}{r}1.1 \\
(-1.8,3.9)\end{array}$ & 0.46 & $\begin{array}{r}-1.6 \\
(-4.9,1.8)\end{array}$ & 0.36 \\
\hline $\begin{array}{l}\text { Pack Years } \\
\text { of Smoking }\end{array}$ & $\begin{array}{r}-0.23 \\
(-0.29,-0.18) \\
\end{array}$ & $1.2 \mathrm{e}-17$ & $\begin{array}{r}-0.055 \\
(-0.098,-0.012) \\
\end{array}$ & 0.012 & $\begin{array}{r}-0.044 \\
(-0.093,0.0053) \\
\end{array}$ & 0.08 & $\begin{array}{r}-0.13 \\
(-0.18,-0.071) \\
\end{array}$ & $1.1 \mathrm{e}-05$ \\
\hline
\end{tabular}

The results of regression coefficients and 95\% confidence intervals are displayed for the overall analysis $(\mathrm{n}=1820)$ and stratified analyses. All models were adjusted for age, body mass index, current smoking status, smoking history in pack years, age at which smoking was started, and level of education completed. In the analysis including all COPDGene ${ }^{\mathbb{B}}$ participants, models were additionally adjusted for a variable indicating COPD case-control status.

Adj $ß=$ =adjusted beta coefficient; $C I=$ confidence interval; PRISm=preserved ratio-impaired spirometry; GOLD=Global initiative for chronic Obstructive Lung Disease

\section{Table 3. The Association of Multiparity and Main Effects of Smoking with Forced Expiratory Volume in One Second Percent Predicted in COPDGene ${ }^{\circledR}$ Participants}

\begin{tabular}{|c|c|c|c|c|c|c|c|c|}
\hline \multirow[t]{2}{*}{ Predictor } & \multicolumn{2}{|l|}{ All } & \multicolumn{2}{|c|}{ No or Mild Obstruction } & \multicolumn{2}{|l|}{ PRISm } & \multicolumn{2}{|c|}{ GOLD Stages 2-4 } \\
\hline & Adj $\beta(95 \% \mathrm{Cl})$ & $p$ value & Adj $\beta(95 \% \mathrm{Cl})$ & $p$ value & $\operatorname{Adj} \beta(95 \% \mathrm{Cl})$ & $p$ value & $\operatorname{Adj} \beta(95 \% \mathrm{Cl})$ & $p$ value \\
\hline $\begin{array}{l}\text { Pack Years } \\
\text { of Smoking }\end{array}$ & $\begin{array}{r}-0.23 \\
(-0.29,-0.18)\end{array}$ & $1.3 e-17$ & $\begin{array}{r}-0.055 \\
(-0.098,-0.012)\end{array}$ & 0.012 & $\begin{array}{r}-0.045 \\
(-0.094,0.0041)\end{array}$ & 0.072 & $\begin{array}{r}-0.13 \\
(-0.18,-0.071)\end{array}$ & $1.1 \mathrm{e}-05$ \\
\hline $\begin{array}{l}\text { Multiparity } \\
\text { (>1 Pregnancy) }\end{array}$ & $\begin{array}{r}-3.8 \\
(-6.5,-1.1)\end{array}$ & 0.0052 & $\begin{array}{r}-2.6 \\
(-4.5,-0.75)\end{array}$ & 0.006 & $\begin{array}{r}0.56 \\
(-2.1,3.3)\end{array}$ & 0.68 & $\begin{array}{r}-1.7 \\
(-4.9,1.5)\end{array}$ & 0.29 \\
\hline
\end{tabular}

The results of regression coefficients and 95\% confidence intervals are displayed for the overall analysis $(n=1820)$ and stratified analyses. All models were adjusted for age, body mass index, current smoking status, smoking history in pack years, age at which smoking was started, and level of education completed. In the analysis including all COPDGene ${ }^{\mathbb{R}}$ participants, models were additionally adjusted for a variable indicating COPD case-control status.

Adj $ß=$ =adjusted beta coefficient; $\mathrm{CI}=$ confidence interval; PRISm=preserved ratio-impaired spirometry; GOLD=Global initiative for chronic Obstructive Lung Disease

associated with lower lung function as measured by $\mathrm{FEV}_{1} \%$ predicted. However, we did not observe this effect in 418 individuals from NHANES without obstruction with no or minimal smoking exposure. Finally, we report that multiparity was not associated with quantitative emphysema or airway disease measured on CT scan.

The current study extends prior evidence regarding parity and lung function. A recent longitudinal prospective cohort study of 120 pregnant females compared spirometry in nulliparous and multiparous females during the first and third trimesters of pregnancy; compared to nulliparas, multiparas had lower $\mathrm{FEV}_{1}, \mathrm{FEF}_{25-75}$, and FVC in the third trimester ${ }^{20}$; however, no post-partum follow-up of lung function was reported. In our study, we compare lung function in multiparas to individuals with 1 or no pregnancies within smoking individuals from the COPDGene ${ }^{\circledR}$ study. When analyzing all COPDGene ${ }^{\circledast}$ participants together, multiparity was associated with lower $\mathrm{FEV}_{1} \%$ predicted. After stratifying by controls (no or mild airflow obstruction) and cases (GOLD 2-4), we observe that this relationship holds true only within the stratum of smokers with no or mild obstruction. One potential explanation for this observation is that individuals in GOLD 2-4 have already lost significant lung function, and factors other than parity (e.g., ongoing smoking exposure) may play a more prominent role in the later 
Figure 3A. Forced Expiratory Volume in One Second Percent Predicted Stratified by Quintiles of Age and Multiparity Status in COPDGene ${ }^{\circledR}$ Participants: All Participants

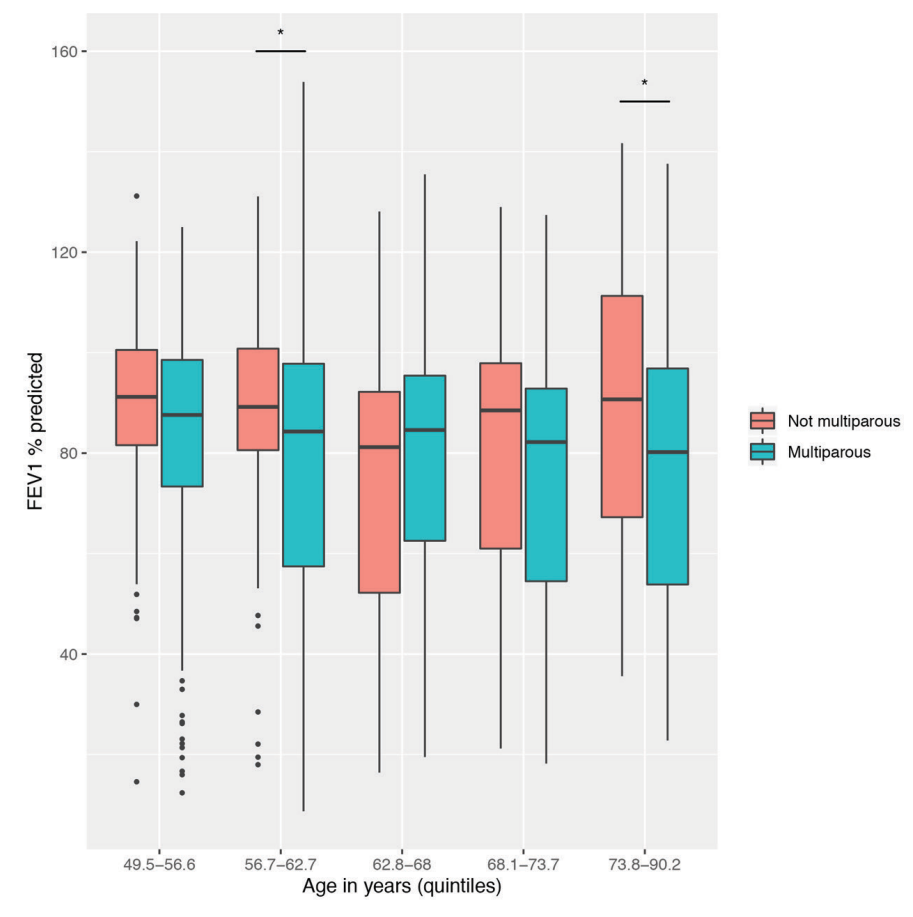

$\mathrm{n}=1820$

${ }^{*} p$ value $<0.05$

$\mathrm{FEV}_{1}=$ forced expiratory volume in 1 second

stages of disease progression. Another explanation may be that GOLD 2-4 participants were older, and age can lead to $\mathrm{FEV}_{1}$ decline independent of smoking and parity (see conceptual model in Figure 2). Thus, we propose that multiparity may be a susceptibility factor for low lung function in smokers with no or mild obstruction.

To assess whether multiparity is a risk factor for lower lung function in persons with no or lower smoking exposure, we evaluated the association between multiparity and $\mathrm{FEV}_{1} \%$ predicted in NHANES; as expected, we did not observe this association in NHANES never smokers or the lower smoking exposure group. There may be several reasons for this result. There may be a required threshold of smoking exposure to evoke the impact of hormones on lung function; the NHANES sample had an average of 8 pack years of smoking; by contrast, the COPDGene ${ }^{\oplus}$ sample had an average of 37 pack years of smoking

\section{Figure 3B. Forced Expiratory Volume in One Second Percent Predicted Stratified by Quintiles of Age and Multiparity Status in COPDGene ${ }^{\circledR}$ Participants: No or Mild Obstructiona $^{a}$}

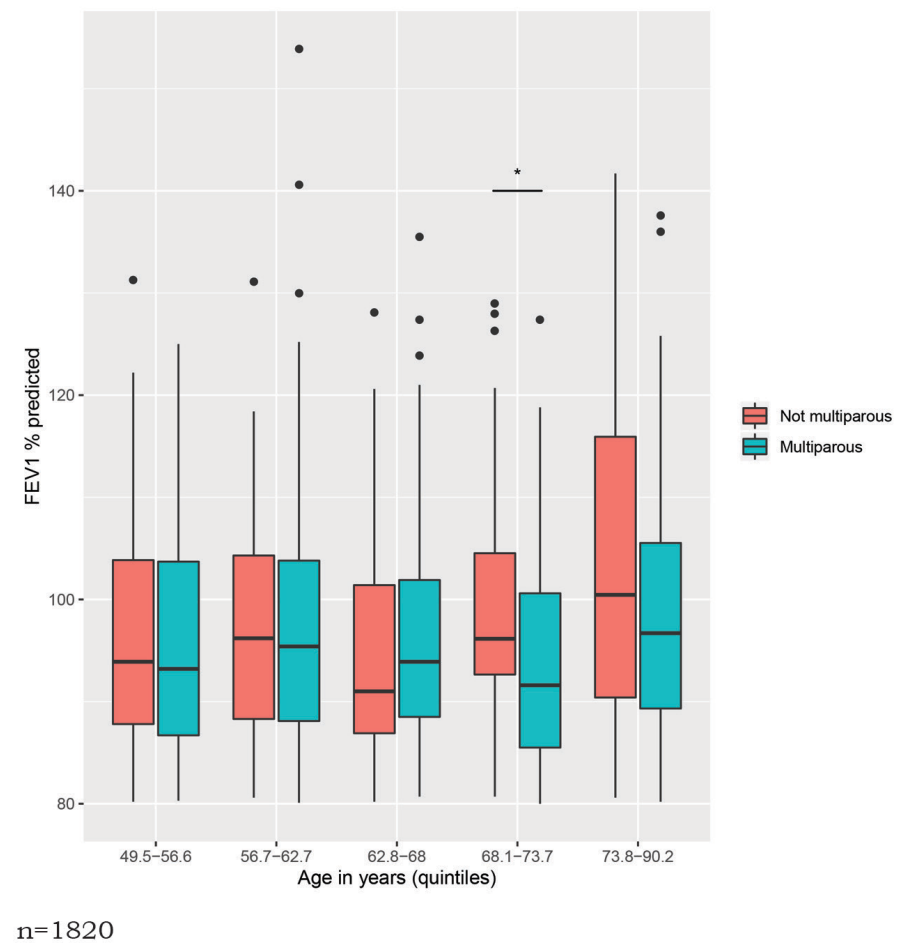

$\mathrm{n}=1820$

${ }^{*} p$ value $<0.05$

$\mathrm{FEV}_{1}=$ forced expiratory volume in 1 second

history. We did not observe a significant interaction between multiparity and smoking on lung function, but we may not have been sufficiently powered to detect this interaction. Perhaps there was an effect in NHANES participants, but we were not powered to detect it given the small sample size. Finally, there is a possibility that the effect observed in COPDGene ${ }^{\circledR}$ is a false positive, and given the potential implications of such a finding, investigation in a sample with similar smoking history is warranted.

One biologically plausible link to explain an association between multiparity and lower lung function in smokers is autoimmunity. Cigarette smoking has been shown to increase oxidative stress, alter immune function, pre-dispose to infections, and has been implicated in the development of autoimmune diseases. ${ }^{29}$ There is also growing evidence that autoimmunity may contribute to COPD pathogenesis. ${ }^{30,31}$ Autoantibodies have 
Figure 3C. Forced Expiratory Volume in One Second Percent Predicted Stratified by Quintiles of Age and Multiparity

Status in COPDGene ${ }^{\circledR}$ Participants:

Preserved Ratio-Impaired Spirometry

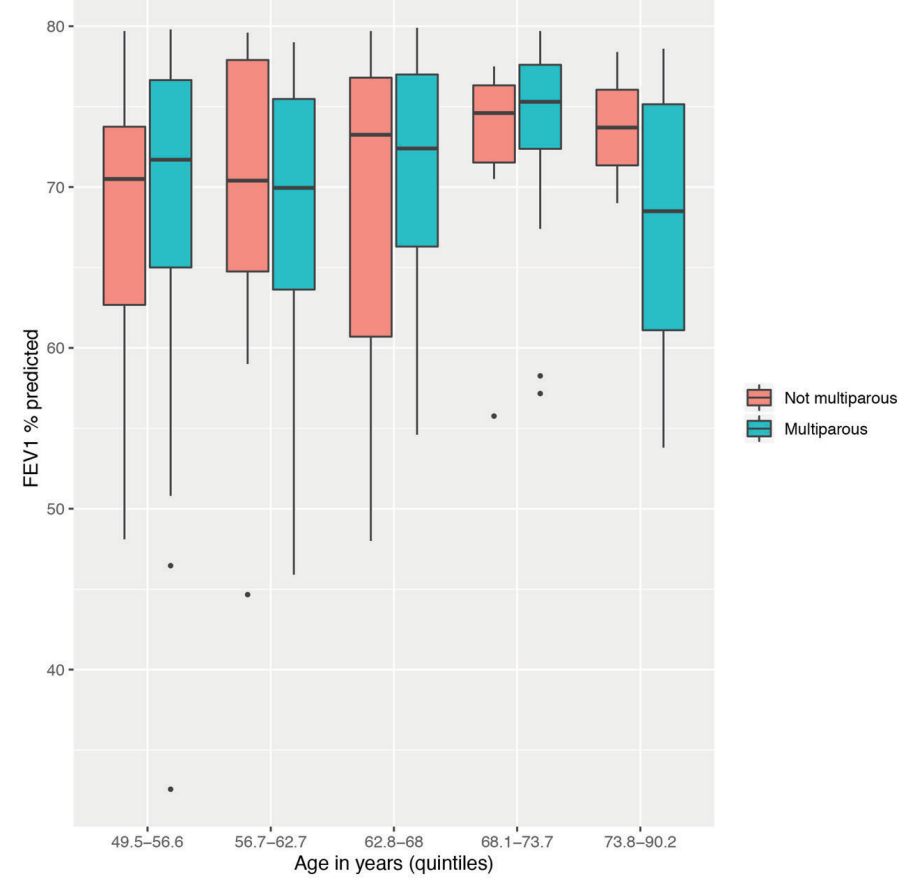

$\mathrm{n}=220$

$\mathrm{FEV}_{1}=$ forced expiratory volume in 1 second
Figure 3D. Forced Expiratory Volume in One Second Percent Predicted Stratified by Quintiles of Age and Multiparity Status in COPDGene ${ }^{\circledR}$ Participants: Global Initiative for Chronic Obstructive Lung Disease 2-4

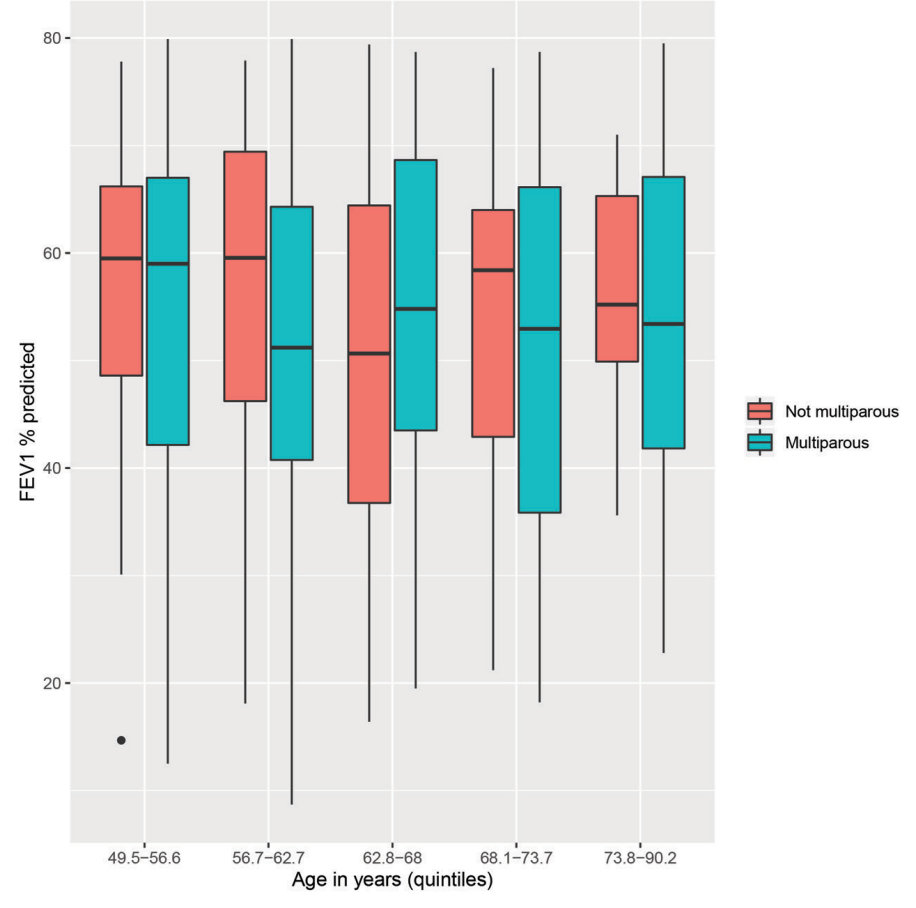

$\mathrm{n}=616$

$\mathrm{FEV}_{1}=$ forced expiratory volume in 1 second

Table 4. The Association of Number of Pregnancies and Multiparity with Forced Expiratory Volume in One Second Percent Predicted in National Health and Nutrition Examination Survey Participants

\begin{tabular}{l|c|c|c|c|c|c}
\hline \multirow{2}{*}{ Predictor } & \multicolumn{3}{c}{ Never Smokers } & \multicolumn{3}{c}{ Lower Smoking Exposure } \\
\cline { 2 - 8 } & Adj $\beta$ & $(95 \% \mathrm{Cl})$ & $p$ value & Adj $\beta$ & $(95 \% \mathrm{Cl})$ & $p$ value \\
\hline 2 Pregnancies & 3.7 & $(-4.7,12)$ & 0.39 & -0.56 & $(-11,9.9)$ & 0.92 \\
\hline 3 or More Pregnancies & 4.5 & $(-3.5,13)$ & 0.27 & 4.3 & $(-5.7,14)$ & 0.39 \\
\hline Multiparity (> 1 Pregnancy) & 4.2 & $(-3.3,12)$ & 0.27 & 2.5 & $(-7.4,12)$ & 0.62 \\
\hline
\end{tabular}

The results of regression coefficients and $95 \%$ confidence intervals are displayed for never smokers $(\mathrm{n}=321)$ and the lower smoking exposure group $(\mathrm{n}=97)$. All models were adjusted for age, body mass index, pack years of smoking, current smoking status, and level of education completed.

Adj $ß=$ adjusted beta coefficient; $\mathrm{CI}=$ confidence interval

been found in sera from individuals with COPD. ${ }^{30}$ Pregnancy-associated plasma protein-A (PAPP-A), a metalloproteinase secreted by placenta, was found to be elevated in COPD individuals, ${ }^{32}$ though this was a small study without external replication. Antigen presenting cells (APCs) from patients with emphysema activate T-helper 1 (Th1) and Th 17 cells, and transfer of APCs recapitulates emphysema in recipient mice 
independent of smoking exposure. ${ }^{33}$ Moreover, a recent network analysis of microarray data showed that activation of $\mathrm{B}$ cell pathways is associated with severe COPD. ${ }^{34}$ While a sex-specific analysis was not performed in this microarray study, it is important to note that females are predisposed to developing many autoimmune disorders, ${ }^{35}$ and that estrogen appears to regulate $\mathrm{B}$ cell antibody production and $\mathrm{T}$ cell-mediated inflammation. ${ }^{36}$ With these data in mind, we propose that multiparity in the presence of cigarette smoke may provide a 'second hit' for immune dysregulation. Indeed, multiparity may be a set up for the development of autoimmunity. For example, in cases of maternofetal hemorrhage, maternal exposure to fetal blood positive for Rhesus antigen can predispose to hemolytic reactions in subsequent pregnancies complicated by maternofetal hemorrhage. ${ }^{37}$ Parity itself has been linked to autoimmunity, which can be influenced by genetic predisposition and epigenetics. ${ }^{38}$ There are also complex alterations in the immune system during pregnancy. ${ }^{39}$ Several autoimmune diseases improve in pregnancy (e.g., Graves' disease 40 ), while others worsen (e.g., systemic lupus erythematosis ${ }^{41}$ ). Development of autoimmune diseases, such as type I autoimmune diabetes, have been reported long after delivery. ${ }^{42}$ A potential mechanism for this delayed autoimmunity is transplacental transfer of cells between mother and fetus (microchimerism), ${ }^{43}$ although this has not been specifically studied in relevance to lung disease. Therefore, it is possible that there is an, as yet unidentified, link between female sex, pregnancy, autoimmunity, and COPD susceptibility and disease progression. Future research could focus on unraveling the complexity of this hypothesis.

Many studies have reported health effects associated with multiple pregnancies. ${ }^{44-47}$ Increased numbers of lifetime pregnancies has also been associated with accelerated markers of aging (including telomere length), ${ }^{48}$ and oxidative stress. ${ }^{49}$ Indeed, aging is an important risk factor for lung function decline, and we observed significant interaction between multiparity and age on $\mathrm{FEV}_{1} \%$ predicted. We do note that, while the interaction term was significant based on the $p$-value, the confidence interval overlaps zero; this likely reflects that the interaction between age and multiparity on lung function appear more significant at lower and higher extremes of age in our cohort. Observing this interaction in the lower range of age categories may imply that smoking exposure at a younger age could have longer term impacts on lung function decline. The interactions in the older age categories may represent an acceleration of the lung function decline seen in normal aging. As individuals age, collagen and elastin deteriorate, chest wall compliance decreases, and respiratory muscle strength diminishes, all leading to lower $\mathrm{FEV}_{1}$ and FVC. ${ }^{50}$ Structurally, the alveolar spaces increase without inflammation or destruction of alveolar walls, and these changes are more pronounced in certain smokers. ${ }^{50,51}$ This may explain why we are detecting changes in lung function without structural changes on CT imaging; multiparous smokers may experience accelerated aging leading to accelerated lung function decline. Furthermore, we note that, in GOLD 2-4 participants from COPDGene ${ }^{\circledR}$, multiparity was associated with higher Pi10, a marker of airway wall thickness; this likely represents the more advanced age of this subgroup. Future investigations can explore the link between aging, multiparity, and lung structure and function.

One strength of our study is the novelty of the potential link between multiparity and lung health in current and former smokers and that we tested our hypothesis in a relatively large sample of female smokers with detailed information regarding number of pregnancies. We explored the effects of cigarette smoking exposure on the association between multiparity and lung function and demonstrate in an independent general population sample that this effect is not present in individuals with lower or no smoking exposure. It is important to note that even lower amounts of smoking exposure can have other harmful effects, and that given the small sample size of the lower smoking exposure group, our data further emphasize the need for young females of child-bearing age to abstain from smoking. Physiologically, these data suggest that endogenous hormones and parity may alter COPD disease susceptibility and progression in smokers and we present several speculations as to a role for autoimmunity and accelerated aging as potential drivers of COPD in women.

This study has several limitations. A larger replication sample is needed to support an interaction between smoking and parity. Perhaps a general population sample with similar smoking history may have replicated the association between multiparity and lower $\mathrm{FEV}_{1} \%$ predicted. While the COPDGene ${ }^{\circledR}$ study provided a considerably large sample in terms of the 
availability of exposure data, we are unable to exclude the possibility of selection bias or overfitting. Further investigation in additional cohorts would be ideal. It is also not clear how hormone replacement therapy may alter the relationship between multiparity and lung function, and we were unable to address this important question because of missingness in the dataset. Additionally, we did not have detailed data regarding the timing between pregnancies and lung function assessments, so we were unable to longitudinally model the effects of parity on lung function. Another issue is that hormone-related exposures were obtained by questionnaire, which introduces the potential for recall bias. However, we expect that most females would remember these major life events with high accuracy (e.g., number of pregnancies). Finally, we did not include serum biomarkers (e.g., PAPP-A, measures of autoantibodies); this information may have lent biological insights into the observed associations but represents a direction for future investigation.

In conclusion, multiparity is associated with lower $\mathrm{FEV}_{1}$ in smokers, but not in those with no or lower smoking exposure. The biological mechanisms underlying this association are unclear but may involve mechanisms of accelerated aging or autoimmunity. While these findings need further investigation into the biological underpinnings, our findings further emphasize that it is of utmost importance for women of child-bearing age to abstain from smoking.

\section{Acknowledgements}

Author Contributions: Matthew Moll, Elizabeth Regan, Barry Make, and Dawn L. DeMeo contributed to study design. Matthew Moll and Dawn L DeMeo performed statistical analyses. Edwin K. Silverman, Dawn L. DeMeo, and James D. Crapo obtained funding. All authors were responsible for the acquisition, analysis, interpretation of data, and for critical revisions of the manuscript.

\section{Declaration of Interest}

MM is supported by National Institutes of Health grant T32HL007427. DLD is supported by P01 HL 114501 and P01 132825. EKS is supported by P01 HL114501, R01 HL133135, R01 HL137927, and R01 HL147148. JDC and EKS are supported by U01 HL089897 and U01 HL089856. SML is supported by National Heart, Lung and Blood Institute grant K01HL 125858.

EKS received grant and travel support from GlaxoSmithKline and grant support from Bayer. DLD has received grant support from Bayer. 


\section{References}

1. Vogelmeier CF, Criner GJ, Martinez FJ, et al. Global strategy for the diagnosis, management, and prevention of chronic obstructive lung disease 2017 Report. GOLD executive summary. Am J Respir Crit Care Med. 2017;195(5):557-582. doi: https://doi.org/10.1164/rccm.201701-0218PP

2. Shapiro SD, Ingenito EP. The pathogenesis of chronic obstructive pulmonary disease: advances in the past 100 years. Am J Respir Cell Mol Biol. 2005;32(5):367-372.

doi: https://doi.org/10.1165/rcmb.F296

3. Mannino DM, Homa DM, Akinbami LJ, Ford ES, Redd SC. Chronic obstructive pulmonary disease surveillance-United States, 1971-2000. MMWR Surveill Summ. 2002;51(6):1-16. https://www.cdc.gov/mmwr/preview/mmwrhtml/ss5106a 1.htm Accessed February 2020.

4. Sin DD, Greaves L, Kennedy S. The tip of the "ICEBERGS": a national conference to combat the growing global epidemic of COPD in women. Proc Am Thorac Soc. 2007;4(8):669-670. doi: https://doi.org/10.1513/pats.200706-083SD

5. Greaves LJ, Richardson LA. Tobacco use, women, gender, and chronic obstructive pulmonary disease: are the connections being adequately made? Proc Am Thorac Soc. 2007;4(8):675-679. doi: https://doi.org/10.1513/pats.200706-079SD

6. Plank-Bazinet JL, Kornstein SG, Clayton JA, et al. A report of the Women's Health Congress workshop on the health of women of color: a critical intersection at the corner of sex/gender and race/ ethnicity. J Women's Heal. 2016;25(1):4-10. doi: https://doi.org/10.1089/jwh.2015.5666

7. Gold DR, Wang X, Wypij D, Speizer FE, Ware JH, Dockery DW. Effects of cigarette smoking on lung function in adolescent boys and girls. N Engl J Med. 1996;335(13):931-937.

doi: https://doi.org/10.1056/NEJM199609263351304

8. Gan WQ, Man SFP, Postma DS, Camp P, Sin DD. Female smokers beyond the perimenopausal period are at increased risk of chronic obstructive pulmonary disease: a systematic review and meta-analysis. Respir Res. 2006;7:52.

doi: https://doi.org/10.1186/1465-9921-7-52

9. Silverman EK, Chapman HA, Drazen JM, et al. Genetic epidemiology of severe, early-onset chronic obstructive pulmonary disease. Risk to relatives for airflow obstruction and chronic bronchitis. Am J Respir Crit Care Med. 1998;157(6 Pt 1):1770-1778.

doi: https://doi.org/10.1164/ajrccm.157.6.9706014

10. Silverman EK, Weiss ST, Drazen JM, et al. Gender-related differences in severe, early-onset chronic obstructive pulmonary disease. Am J Respir Crit Care Med. 2000;162(6):2152-2158. doi: https://doi.org/10.1164/ajrccm.162.6.2003112
11. Foreman MG, Zhang L, Murphy J, et al. Early-onset chronic obstructive pulmonary disease is associated with female sex, maternal factors, and African American race in the COPDGene ${ }^{\circledast}$ study. Am J Respir Crit Care Med. 2011;184(4):414-420. doi: https://doi.org/10.1164/rccm.201011-1928OC

12. Ben-Zaken Cohen S, Paré PD, Man SFP, Sin DD. The growing burden of chronic obstructive pulmonary disease and lung cancer in women: examining sex differences in cigarette smoke metabolism. Am J Respir Crit Care Med. 2007;176(2):113-120. doi: https://doi.org/10.1164/rccm.200611-1655PP

13. Martinez FJ, Curtis JL, Sciurba F, et al. Sex differences in severe pulmonary emphysema. Am J Respir Crit Care Med. 2007; 176(3):243-252.

doi: https://doi.org/10.1164/rccm.200606-828OC

14. Sathish V, Martin YN, Prakash YS. Sex steroid signaling: implications for lung diseases. Pharmacol Ther. 2015;150:94-108. doi: https://doi.org/10.1016/j.pharmthera.2015.01.007

15. Cashman JR, Park SB, Yang ZC, Wrighton SA, Jacob P, Benowitz NL. Metabolism of nicotine by human liver microsomes: stereoselective formation of trans-nicotine N'-oxide. Chem Res Toxicol. 5(5):639-646. doi: https://doi.org/10.1021/tx00029a008

16. Sin DD, Cohen SB-Z, Day A, Coxson H, Pare PD. Understanding the biological differences in susceptibility to chronic obstructive pulmonary disease between men and women. Proc Am Thorac Soc. 2007;4(8):671-674.

doi: https://doi.org/10.1513/pats.200706-082SD

17. Mollerup S, Ryberg D, Hewer A, Phillips DH, Haugen A. Sex differences in lung CYP1A 1 expression and DNA adduct levels among lung cancer patients. Cancer Res. 1999;59(14):3317-3320. https://www.semanticscholar.org/paper/Sex-differences-inlung-CYP1A1-expression-and-DNA-Mollerup-Ryberg/8f01cbe5 c51fb1154bcce192235db4ab14318c7f. Accessed February 2020.

18. Berge G, Mollerup S, $\varnothing$ Vrebø S, et al. Role of estrogen receptor in regulation of polycyclic aromatic hydrocarbon metabolic activation in lung. Lung Cancer. 2004;45(3):289-297. doi: https://doi.org/10.1016/j.lungcan.2004.02.014

19. Triebner K, Matulonga B, Johannessen A, et al. Menopause is associated with accelerated lung function decline. Am J Respir Crit Care Med. 2017;195(8):1058-1065. doi: https://doi.org/10.1164/rccm.201605-0968OC

20. Pastro LDM, Lemos M, Fernandes FLA, et al. Longitudinal study of lung function in pregnant women: influence of parity and smoking. Clinics (Sao Paulo). 2017;72(10):595-599. doi: https://doi.org/10.6061/clinics/2017(10)02

21. Regan EA, Hokanson JE, Murphy JR, et al. Genetic Epidemiology of COPD (COPDGene ${ }^{\circledR}$ ) study design. COPD. 2011;7(1):32-43. doi: https://doi.org/10.3109/15412550903499522 
22. Nurses' Health Study. Questionnaires. Nurses' Health Study website. https://www.nurseshealthstudy.org/participants/ questionnaires. Published 2016. Accessed February 2020.

23. Alsammani MA, Ahmed SR. Grand multiparity: risk factors and outcome in a tertiary hospital: a comparative study. Mater Sociomed. 2015;27(4):244-247.

doi: https://doi.org/10.5455/msm.2015.27.244-247

24. Centers for Disease Control and Prevention (CDC), National Center for Health Statistics. National Health and Nutrition Examination Survey, 2011-2012 data set. CDC website. https:// www.cdc.gov/nchs/nhanes/index.htm Accessed February 2020.

25. Hankinson JL, Odencrantz JR, Fedan KB. Spirometric reference values from a sample of the general U.S. population. Am J Respir Crit Care Med. 1999;159(1):179-187.

doi: https://doi.org/10.1164/ajrccm.159.1.9712108

26. Han MK, Kazerooni EA, Lynch DA, et al. Chronic obstructive pulmonary disease exacerbations in the COPDGene ${ }^{\circledR}$ study: associated radiologic phenotypes. Radiology. 2011;261(1):274282. doi: https://doi.org/10.1148/radiol.11110173

27. Van Tho N, Ogawa E, Trang LTH, et al. A mixed phenotype of airway wall thickening and emphysema is associated with dyspnea and hospitalization for chronic obstructive pulmonary disease. Ann Am Thorac Soc. 2015;12(7):988-996. doi: https://doi.org/10.1513/AnnalsATS.201411-501OC

28. Wan ES, Castaldi PJ, Cho MH, et al. Epidemiology, genetics, and subtyping of preserved ratio impaired spirometry (PRISm) in COPDGene ${ }^{\circledR}$. Respir Res. 2014;15:89. doi: https://doi.org/10.1186/s12931-014-0089-y

29. PerriconeC,Versini M,Ben-AmiD, etal.Smokeand autoimmunity: the fire behind the disease. Autoimmun Rev. 2016;15(4):354-374. doi: https://doi.org/10.1016/j.autrev.2016.01.001

30. Wen L, Krauss-Etschmann S, Petersen F, Yu X. Autoantibodies in chronic obstructive pulmonary disease. Front Immunol. 2018;9:66. doi: https://doi.org/10.3389/fimmu.2018.00066

31. Kheradmand F, Shan M, Xu C, Corry DB. Autoimmunity in chronic obstructive pulmonary disease: clinical and experimental evidence. Expert Rev Clin Immunol. 2012;8(3):285292. doi: https://doi.org/10.1586/eci.12.7

32. Talay F, Tosun M, Yaşar ZA, et al. Evaluation of pregnancyassociated plasma protein-a levels in patients with chronic obstructive pulmonary disease and associations with disease severity. Inflammation. 2016;39: 1136-1133. doi: https://doi.org/10.1007/s10753-016-0345-z

33. Shan M, Yuan X, Song L-z, et al. Cigarette smoke induction of osteopontin (spp1) mediates th17 inflammation in human and experimental emphysema. Sci Transl Med. 2012;4(117):117ra9117ra9. doi: https://doi.org/10.1126/scitranslmed.3003041
34. Morrow JD, Zhou X, Lao T, et al. Functional interactors of three genome-wide association study genes are differentially expressed in severe chronic obstructive pulmonary disease lung tissue. Sci Rep. 2017;7(1):44232. doi: https://doi.org/10/1038/ srep44232

35. Eaton WW, Rose NR, Kalaydjian A, Pedersen MG, Mortensen PB. Epidemiology of autoimmune diseases in Denmark. $J$ Autoimmun. 2007;29(1):1-9.

doi: https://doi.org/10.1016/j.jaut.2007.05.002

36. Straub RH. The complex role of estrogens in inflammation. Endocr Rev. 2007;28(5):521-574.

doi: https://doi.org/10.1210/er.2007-0001

37. Avent ND, Reid ME. The Rh blood group system: a review. Blood. 2000;95(2):375-387. doi: https://doi.org/10.1182/blood.V95.2.375

38. Ngo ST, Steyn FJ, McCombe PA. Gender differences in autoimmune disease. Front Neuroendocrinol. 2014;35(3):347369. doi: https://doi.org/10.1016/j.yfrne.2014.04.004

39. Piccinni M-P, Lombardelli L, Logiodice F, Kullolli O, Parronchi P, Romagnani S. How pregnancy can affect autoimmune diseases progression? Clin Mol Allergy. 2016;14:11. doi: https://doi.org/10.1186/s12948-016-0048-x

40. Weetman AP. Immunity, thyroid function and pregnancy: molecular mechanisms. Nat Rev Endocrinol. 2010;6(6):311-318. doi: https://doi.org/10.1038/nrendo.2010.46

41. Jara LJ, Medina G, Cruz-Dominguez P, Navarro C, Vera-Lastra O, Saavedra MA. Risk factors of systemic lupus erythematosus flares during pregnancy. Immunol Res. 2014;60(2-3):184-192. doi: https://doi.org/10.1007/s 12026-014-8577-1

42. Negishi M, Shimomura K, Proks P, et al. Development of postpartum Graves' disease and type 1 diabetes after delivery in a patient with gestational diabetes. $J$ Diabetes Investig. 2011;2(4):328-330.

doi: https://doi.org/10.1111/j.2040-1124.2010.00089.x

43. O’Donoghue K. Pregnancy and the risk of autoimmune disease: an exploration. Chimerism. 2011;2(3):84-85. doi: https://doi.org/10.4161/chim.17771

44. Ben Saad H, Rouatbi S, Raoudha S, et al. Vital capacity and peak expiratory flow rates in a North-African population aged 60 years and over: influence of anthropometric data and parity. Rev Mal Respir. 2003;20(4):521-530.

45. Lambe M, Lindblad P, Wuu J, Remler R, Hsieh C. Pregnancy and risk of renal cell cancer: a population-based study in Sweden. $\mathrm{Br}$ $J$ Cancer. 2002;86(9):1425-1429.

doi: https://doi.org/10.1038/sj.bjc.6600263

46. Jacobs MB, Kritz-Silverstein D, Wingard DL, Barrett-Connor E. The association of reproductive history with all-cause and cardiovascular mortality in older women: the Rancho Bernardo Study. Fertil Steril. 2012;97(1):118-124.

doi: https://doi.org/10.1016/j.fertnstert.2011.10.028 
47. Humphries KH, Westendorp IC, Bots ML, et al. Parity and carotid artery atherosclerosis in elderly women: the Rotterdam Study. Stroke. 2001;32(10):2259-2264. doi: https://doi.org/10.1161/hs1001.097224

48. Ryan CP, Hayes MG, Lee NR, et al. Reproduction predicts shorter telomeres and epigenetic age acceleration among young adult women. Sci Rep. 2018;8(1):11100.

doi: https://doi.org/10.1038/s41598-018-29486-4

49. Ziomkiewicz A, Sancilio A, Galbarczyk A, Klimek M, Jasienska G, Bribiescas RG. Evidence for the cost of reproduction in humans: high lifetime reproductive effort is associated with greater oxidative stress in post-menopausal women. PLoS One. 2016;11(1):e0145753.

doi: https://doi.org/10.1371/journal.pone.0145753

50. Brandsma C-A, de Vries M, Costa R, Woldhuis RR, Königshoff $\mathrm{M}$, Timens W. Lung ageing and COPD: is there a role for ageing in abnormal tissue repair? Eur Respir Rev. 2017;26(146).

doi: https://doi.org/10.1183/16000617.0073-2017

51. Lamb D, Gillooly M, Farrow AS. Microscopic emphysema and its variations with age, smoking, and site within the lungs. Ann NY Acad Sci. 1991;624(1):339-340.

doi: https://doi.org/10.1111/j.1749-6632.1991.tb17040.x 